\title{
Personal Projections in Artists' Works: Implications for Branding
}

Judi Harris

College of William and Mary

Follow this and additional works at: https://scholarworks.wm.edu/educationpubs

Part of the Education Commons

\section{Recommended Citation}

Harris, J.B. (2007). Personal projections in artists' works: Implications for branding. Journal of Brand Management, 14(3), 295-312.

This Article is brought to you for free and open access by the School of Education at W\&M ScholarWorks. It has been accepted for inclusion in School of Education Articles by an authorized administrator of W\&M ScholarWorks. For more information, please contact scholarworks@wm.edu. 


\title{
Personal projections in artists' works: Implications for branding
}

Received (in revised form): 20th October, 2006

JUDITH B. HARRIS

Keywords

projective drawings; branding; personality

\begin{abstract}
This paper summarises the findings of an in-depth, qualitative study of the communicative qualities of 10-year-olds' artistic productions in several media: pen-and-paper, digital graphics created with a touch tablet and the programming language Logo. Sixty-nine per cent of viewing teachers' statements about the children's learning preferences, styles and personal attributes were confirmed with information shared by the children's teachers, parents and the children themselves during interviews. There were no discernible differences in the accuracy of perceptions among works developed with different production media. Viewing teachers knew nothing about the children's ages, genders, backgrounds, school experiences, preferences or other personal attributes. The results of this study, considered within the context of long-standing literature on the use of artistic works as projective devices with children and adults for psychological assessments, suggests that brand symbols and logos may reveal information about their creators that is perceived subconsciously by potential consumers and that could influence consumer behaviour. Recommendations for further research to confirm or refute this supposition are offered. Journal of Brand Management (2007) 0, 000-000. doi:10.1057/palgrave.bm.2550072
\end{abstract}

'Discovery consists of looking at the same thing as everyone else and thinking something different'.

-Albert Szent-Gyorgyi ${ }^{1}$

\section{INTRODUCTION}

A commonly held understanding among educators and psychologists is that people symbolically communicate aspects of themselves and their experiences in their artistic works. Teachers-especially those working with children and pre-adolescents-are encouraged to use every source of information available to help them to understand their pupils' learning needs and preferences as thoroughly as possible: observations of students' behaviour; the content of their writing; their parents' comments; the error patterns evident in their homework assignments; their standardised test scores and even their artwork.

Teachers can become frustrated with educational researchers' apparent lack of awareness of how well many know their students, how they come to gain that knowledge, and how they use it to assist students' learning. The use of collaborative, systematic child study processes, such as Carini's ${ }^{2}$ highly structured 'descriptive review' of children's art, writing and mathematical problem-solving demonstrates that teachers can glean important information about both their own and other teachers' students by examining and reflecting carefully upon the students' works together. The educational research described in this paper was designed, in a sense, with hopes of validating the reality 
of this 'practitioners' truth;' to discover what verifiable information viewing teachers can accurately infer about young artists by examining their graphic creations.

After the study was conducted, results were shared with educational researchers through publication and presentation. Recently, the editor of this special issue of The Journal of Brand Marketing suggested that the same study's results, reframed in terms of implications for branding, may be of interest to an entirely different community of scholars. Our e-mailed discussions of her idea resulted in this paper, in which an analysis of the perceived projected content of ten elementary students' drawings done in three different media is presented. As Szent-Gyorgyi's statement above describes it, the 'discovery' here-that is, the cross-disciplinary connection that the editor made after locating these educational technology research results - is the possibility that this study of the communicative aspects of children's drawings may point the way to similarly focused and productive research in brand development. If children's artwork reflects much personal information to teachers who have never met the young artists, then it is possible that marketing brands (especially logos) communicate similarly about their creators to potential consumers. Given the importance of mirroring to determine consumer choices, and rooted in the empathy principle ${ }^{3}$ of aesthetic experience, this possibility warrants further exploration and discussion.

\section{BRANDS AS COMMUNICATIVE WORKS}

Brands-names and/or symbols intended to identify and differentiate goods or services from each other ${ }^{4}$-are said to have 'personalities', in that they are associated with sets of human characteristics that serve symbolic or self-expressive functions for consumers. The greater the congruity between a brand's personality and a consumer's notions of actual or ideal self, the greater the probability for purchase. ${ }^{5,6}$ Those consumer selves-once thought to be expressed consistently over time and across contexts-are actually rather 'malleable', influenced by either schematic (eg sex or age) or situational selfperceptions. $^{7}$

Brand personality characteristics, including demographics such as gender, age, ethnicity and class, can become associated with brands indirectly through brand symbols or logos. ${ }^{5,8}$ It seems to be assumed generally that these brand characteristics are consciously developed and communicated, both directly and symbolically, as part of the overall marketing strategy for a product.

Might some aspects of a brand's personality be communicated through its symbols or logo without such conscious intent? Current design scholarship points to the probability of this phenomenon. Buchanan, ${ }^{9}$ for example, in tracing the history of design by examining the rhetoric of products-'the study of how products come to be as vehicles of argument and persuasion about the desirable qualities of private and public life' (p. 26)concludes that 'products embody the intentions and purposes of their makers' (p. 55). Some empirical research results are also beginning to demonstrate the reality of brands' reflective qualities vis-à-vis their designers. Moss's study ${ }^{10}$ of adult males' and females' designs and design preferences, for example, showed strong and significant 'like for like' tendencies: both men and women preferred designs created by designers of the same sex as viewers. Later research by Moss, ${ }^{11}$ Moss and 
Colman, ${ }^{12}$ and Moss and Gunn ${ }^{13}$ replicated these findings with both designer and nondesigner participant samples, and using a variety of designed products, from business cards to holiday greetings to websites. Moss relates these results to examples of successful current-day brands with both male and female designers, suggesting that one way of increasing sales among women may be either to hire more female brand designers, who-perhaps unknowingly_communicate their gender through their designs; or designers of either sex who demonstrate clear understanding of a female brand aesthetic.

This notion of symbolic communication of aspects of self is what is central to the possibility of personal projections in artists' and designers' works. Consumer research has explored the symbolic meanings of products, and found them to be often quite social in nature. ${ }^{6}$ This means that goods and services can be seen as tools that are used to communicate indirectly with consumers. Specifically, a product's logo-viewed here as a piece of art — can be seen to contain information that evokes an aesthetic response from the consumer. This response, which is akin to multi-layered, simultaneous discourse due to the work's symbolic nature, is based in a unique personified relationship between the spectator and the work. This 'empathy principle' of the psychology of aesthetic experience is 'a dynamic process that takes place between object and spectator... [who] identifies with the object [and] becomes, so to speak, fused with it'(Crozier and Greenhalgh, ${ }^{3}$ p. 74).

A similar principle is echoed in recent work in visual culture. Rogoff's ${ }^{14}$ examination of scholarship in this field, for example, depicts the visual as inextricably linked with verbal, auditory, emotional, physical, intellectual, spatial, and historical attributes and responses. Thus, to under- stand images (and therefore brands) in post-modernity, their perception and reception must be explored in terms of the "cultural, social, and economical conditions surrounding [their] producers and users' (Fischman, ${ }^{15}$ p. 29) — and as acts that are both passive and active.

The empathy principle could well explain the primary mechanism by which artworks' viewers respond to what they see and otherwise sense. Certainly, the results of the study presented here suggest that children's artistic creations may communicate much more about their artists than generally assumed. If similar findings are found to be true on a larger scale, and with adults' graphic designs, they have broad implications for brand design as it relates to marketing to target populations.

\section{DRAWINGS AS PSYCHOLOGICAL COMMUNICATION}

Moss's work with adult male and female design students ${ }^{10}$ drew upon a considerable body of educational and psychological literature about children's drawings in the absence of similar scholarship to date about projective aspects of brand symbols/ logos. Most research about drawings as psychoassessment tools examines either children's works or adults' creations. A notable exception, however, is Silver's ${ }^{16-18}$ work in art therapy. In studies with large (300-700-member) and heterogeneous samples, using standardised 'stimulus drawing' tasks and well-validated scoring instruments with high inter-rater reliabilities, artists' expressions of emotion, selfimages, attitudes towards self and others, and depictions of relationships were consistently and significantly differentiated by sex, based only upon researchers' reviews of participants' drawings and their titles. Each of these studies was completed 
with approximately equal numbers of participants from four different age groups: children, adolescents, younger adults and the elderly. Silver's work suggests that artists of every age similarly express personal information via their works, and the content and nature of these unconscious communications differ significantly by age and sex.

The study and use of children's drawings as personally communicative devices has a long and rich history in educational inquiry. Children's drawings were first presented as potential psychodiagnostic tools when Corrado Ricci, an art critic with interests in psychology, published the first known reproductions of children's art in 1887. A number of other scholarly studies of children's sketches followed. ${ }^{19}$ These led to Goodenough's ${ }^{20}$ seminal work, which presented the first systematised method for estimating artists' intelligence from drawings of people. This technique was standardised and embellished upon by Harris ${ }^{21}$ and Harris and Roberts. ${ }^{21,22}$ The resulting GoodenoughHarris instrument, called the 'Draw-AMan Test' because the task presented to the child is simply to 'draw a man', is the earliest example of a class of open-ended drawing investigations called human figure drawings (HFDs), which have since been incorporated into several standardised IQ tests for children. Most research with children's drawings completed to date has made use of the HFD or one of its variants.

Among practicing psychologists and educators, it is generally accepted that children's drawings have both 'projective' and 'nonprojective' uses in psychological assessment. 'Projection' is a clinical term used in this context to suggest that an artist unconsciously imbues the picture being drawn with self-perceptions, regardless of the intended focus for the work. There are four types of projections thought to be observable in children's drawings: those that symbolically communicate aspects of personality; perceptions of self in relation to others; values and specific attitudes. Nonprojective indicators in children's artwork include those that 'measure a child's developmental or intellectual maturity' (Klepsch and Logie, ${ }^{19}$ p. 13).

Eighty years of research into projective and nonprojective assessment of children's drawings suggests that it is indeed possible for artist characteristics such as intellectual acuity, developmental maturity, personality, values, atitudes, emotions, behaviour and culture of origin to be reflected through children's artistic works. ${ }^{23,24}$ Practitioners are cautioned, however, not to use such measures alone for diagnosis, since children's works can be reflective of transient emotional states and attitudes toward the topics visually depicted, ${ }^{25}$ and the reliability and validity of specific picture elements' correlations with particular psychopathologies are not consistent across artists. ${ }^{26}$

Professionals who regularly analyse the projective and nonprojective content of children's drawings are trained to assess the works according to the specific protocols of the particular HFD device being used for psychological assessment. In this study, however, a set of questions was created to explore the possibility of untrained viewers' accurate assessments of the symbolic content of children's drawings:

- Can teachers recognise and correctly identify individual artists' traits from viewing their artwork alone?

- Which artist traits are correctly and incorrectly identified?

- Does the accuracy of these informal assessments vary according to the different media that children used to create their pictures? 


\section{CHILDREN'S DRAWING ASSESSMENTS AND VIEWERS' TRAINING}

A sizable body of literature has been directed toward establishing the validity of HFD instrument variants, some of which makes use of untrained or 'naive' judges. Several studies include teachers in this category. In summarising the research on trained and untrained judges' interpretive abilities, Swensen ${ }^{27}$ concluded that 'formal training is not particularly related to success in interpreting the Draw-A-Person Test' (p. 39). Hiler and Nesvig ${ }^{28}$ suggest that 'well-developed intuitive ability rather than formal clinical training is of primary importance in the interpretation of figure drawings' (p. 526).

For the purposes of this study, it was important to extend this hypothesis. Perhaps human beings possess intuitive abilities that can be used to detect and describe verifiable information about artists solely by looking at their works. Moreover, perhaps teachers subconsciously use information gathered in this manner as one of many ways to get to know their students. To consider this possibility, 'intuition' should be defined. This is easier said than done. Noddings and Shore, ${ }^{29}$ after carefully examining the history of the notion, chose to characterise intuitive modes by involvement of both external and internal senses; by a relaxation of distancing into receptivity; by a quest for understanding or insight; and by a continuing tension between subjective certainty and objective uncertainty (p. 89).

Noddings and Shore ${ }^{29}$ go on to say that an individual's will must direct conscious intuitive activity, straining against reason, and the senses must assist the effort by consciously turning inward. This exertion of will, according to these authors, must be motivated by a desire for experiential understanding and enjoyment through embracing what is apparently irrational. To whatever extent the so-called 'untrained' (or intuitive) judges are able to reach, maintain and deepen, these states as they view children's drawings may also be the extent to which they can consciously assert verifiable information about the artists. It is conceivable, however, that subconscious intuitive activity-such as what consumers perceive intuitively when viewing a brand's logo design-could influence attitudes and decisions.

\section{STUDY TYPE}

How, then, might we verify information intuitively received about artists by observers of their works? The following two research questions were formed to organise this study:

- What is the scope of verifiable information communicated through children's digital and freehand drawings?

- How, if at all, does the scope and/or accuracy of information communicated through children's artwork differ when different drawing tools are used by the artists?

Results that address these questions and that may be helpful to marketing researchers investigating the communicative aspects of brand symbols and logos are presented below. More detailed findings are available in Harris. ${ }^{30}$

Yin $^{31}$ suggests that all research questions can be classified as 'who', 'what', 'where', 'why' or 'how' queries. 'Who', 'what' and 'where' questions are often refined to 'how many' and 'how much' questions, which are best approached with quantitative measures, especially when predictive results are desired. 'What' questions can be approached with any research strategy. 'How' and 'why' questions, asked 
about contemporary situations over which the researcher has little or no control, are best explored with case studies. Yin is careful to note that the most frequently cited drawback of case studies - that they are not generalisable to larger populations, reflects a misunderstanding of the intent of case study research. According to Yin, case study results, 'like experiments', are generalisable to theoretical propositions and not to populations or universes. In this sense, the case study, like the experiment, does not represent a 'sample', and the investigator's goal is to expand and generalise theories (analytic generalisation) and not to enumerate frequencies (statistical generalisation)' (p. 21).

Stake $^{32}$ recommends in-depth, casebased studies as the preferred method for social science inquiry because "they may be epistemologically in harmony with the reader's experience and thus to that person a natural basis for generalisation' (p. 5). Stake posits that case study results are therefore more directly relevant to the practitioner in fields such as education and social work. Yin ${ }^{31}$ similarly recommends the case study for empirical inquiry that investigates a contemporary phenomenon within its real-life context when the boundaries between the phenomenon and its context are not clearly evident. This often describes research foci like the one explored in this study, which constitute new connections and directions in research-based inquiry.

Yin $^{31}$ also suggests that multiple case study designs be 'consider[ed] as one would consider multiple experimentsthat is, to follow a replication logic', rather than for the purpose of obtaining larger respondent samples (p. 48). Accordingly, Yin says, multiple data types from multiple sources should be collected for each case, then interpreted and summarised as if each case were a separate study before any cross-case analysis is begun. These notions formed the basis from which the specific methods for data generation and analysis were selected to explore answers to the two research questions presented above.

\section{METHODS}

The exploratory nature of the research questions addressed in this study imply the need for an open-ended exploration of all possible types of information that can be detected about a child artist from his/her work. It is logical, then, to suggest multisource, open-ended, complementary techniques to gather data about the artists. Since teachers' impressions of young artists' personal characteristics were solicited as they viewed children's artistic works, others' perceptions of each child artist were requested for cross-referencing the viewing teachers' intuitively perceived ideas. These were available from the children themselves during self-report interviews, and from significant others in the children's lives-namely, their parents and teachers-who were interviewed in similar semi-structured formats about the children's personal characteristics and preferences. Coded interviews from all participants (children, parents and teachers), and intuited impressions from teachers viewing the children's works, therefore, comprised the data for each case in this research study.

First, the two types of data about the artists (interviews and viewing teachers' impressions) were compared within each case to determine the proportion of intuited information that could be cross-referenced with interview data. Then, across-case analysis was completed to form comparisons among observers and types of information intuited to see if any additional patterns could be detected-for 
example, whether gender was easier to discern than age or whether certain observers intuited information more accurately than others. Since this was an exploratory study, only tentative, logical/ analytical generalisations (as described above by Yin) were sought.

The study used a purposive and convenience sample comprised of gifted fifthgrade boys who were US citizens with at least one parent who had a post-baccalaureate degree. Miles and Huberman ${ }^{33}$ recommend the use of a purposive sample in exploratory, in-depth studies such as this one 'because social processes have a logic and coherence that random sampling of events or treatments usually reduces to uninterpretable sawdust' (p. 36). Patton ${ }^{34}$ suggests that researchers select cases to study that promise the most cogent information about the topic of investigation. $\mathrm{He}$ recommends that these be critical cases.... [those that] make a point quite dramatically or are, for some reason, particularly important' (p. 102). Patton goes on to say that although studying one or a few critical cases does not technically permit broad generalisations to all possible cases, logical generalisations can often be made from the weight of the evidence produced in studying a single, critical case.

Ten children agreed to be informants for this study. All were 9- or 10-year-old males in fifth grade at a public elementary school in a southeastern state when they were interviewed. All had been identified for their school districts' gifted and talented programmes and had qualified for a local university's summer enrichment programme for gifted and talented students. This high degree of demographic similarity was sought so that perceived differences among students might be maximally specific to individual participants' personal attributes. Each student was asked to choose one parent and one teacher to be interviewed about their perceptions of the student. All names were changed to pseudonyms to protect informants' rights to confidentiality.

\section{DATA GENERATION AND ANALYSIS}

The loosely structured interviews of the students, parents and current classroom teachers, each of which was approximately $1 \mathrm{~h}$ in length, were audiotaped and transcribed verbatim. The contents of these transcripts were then analysed by theme using Strauss and Corbin's ${ }^{35}$ recommended methods for grounded theory inquiry. Ethnograph software was used to organise coded data.

All participants were asked to describe the students' most and least favourite school subjects, problem-solving methods, social interaction patterns, personal 'life philosophies' and activity preferences. Study participants provided information in response to all prompts, with the exception of several children who were not able to describe their own metacognitive problem-solving processes. Lists of statements about the artists - each containing one discrete idea (the study's unit of analysis) - were created for each interview by the researcher, using participants' words whenever possible to describe perceived phenomena. Considered together, the lists contained all of the content relevant to the interview prompts in the study. Member checking was done by surface mail, asking study participants to read and correct any interpretive discrepancies made by the researcher in the lists of summarised statements about the students. Of the 1,397 statements that were written and sent to informants, all were read and returned. Fifty-one statements were corrected with respect to content (six 
statements) and wording (47 statements). Overall, only a small fraction-approximately 4 per cent — of the statements were corrected by study participants.

Constant comparative coding revealed 15 mutually exclusive theme categories across interview transcriptions. Coding reliability and validity were ensured by frequent meetings with two peer debriefers and the maintenance and review of the researcher's reflexive methodological $\log .{ }^{36}$ One peer debriefer also reviewed all information generated for a randomly selected case to ensure that summary statements were firmly grounded in generated data.

Immediately prior to being interviewed, each student informant drew three pictures, one in each of three different media. The content and style of the pictures were determined completely by the students; the only instructions given by the researcher regarded the media to use for each drawing. Participants had their choice of crayons, magic markers and coloured pencils to use for the freehand picture; a touch-sensitive graphics tablet ('Touch Window: ${ }^{37}$ ) and digital drawing software ('Animation Station: ${ }^{, 38}$ ) for the picture made with the tablet, and their choice of either IBM Logo, ${ }^{39}$ Apple Logo $\mathrm{II}^{40}$ or LogoWriter ${ }^{41}$ software for the Logo picture. All computer-assisted pictures were drawn on Apple IIe computers, with the exception of one Logo picture created on an IBM PC. All of the students had learned to use Logo before participating in this study.

Participants gave the researcher permission to keep the pictures the students created and show them to teachers who had not met the children. Two groups of teachers viewed the pictures and responded to them. One group, comprised of five teachers, were graduate students taking a summer Logo course in New York, and the others (nine teachers) were graduate students completing Logo-based coursework during the same summer session in Oregon. All had previously worked with Logo with elementary-aged children in instructional settings. The two graduate course instructors received $35 \mathrm{~mm}$ slide reproductions of the children's pictures, arranged in a standard order in a slide carousel, and sufficient copies of a paperbased viewer response form to provide one for each of the graduate students in their classes. The instructors were then asked to follow the viewing instructions printed on the first page of the response form. Pictures formed with similar media were grouped together in the slide carousel, but the artist order in each media-related group was different.Viewers were told only that children drew the 30 pictures; they did not know that ten artists produced all of the works, nor did they know anything about the each child's age, gender, computer experience, or exceptionality.

Two types of intuited information were requested of the viewing teachers. The first was specific answers to specific questions about the children (such as age and gender); the second was viewer-supplied comments about the students' learning styles, school subject preferences, behaviour patterns, and any other information that occurred to the viewing teachers. All viewing teachers but one completed the response forms in full. The contents of all response forms were first rewritten as lists of statements about the student artists, following the same procedure as was used to process interview data described above. These lists of statements were then analysed using constant comparative techniques for data analysis, ${ }^{35}$ yielding eight mutually exclusive coding categories. Answers to both specific and open-ended questions-in 
the form of lists of statements about each of the ten artists-on the viewer response form were cross-referenced with interview data to determine agreement or lack thereof.

Levels of agreement between viewing teacher comments and interview data were classified as 'agree', 'disagree', 'agree by implication', 'disagree by implication', or 'not mentioned'. If the content of a particular viewer's statement about an artist was mentioned in two or more interviews with people who knew the artist (parent, teacher, self), the statement was assumed to agree with interview data. If the obverse of the content of a particular viewer conjecture was mentioned in two or more interviews, the viewing teacher's statement was assumed to disagree with interview data. If the content was implied, but not stated directly in interview data from at least two people who knew the artist, it was assumed to agree by implication. Similarly, if the content of a viewer comment was countered indirectly in two or more interviews, then it was assumed to disagree by implication. If the content of a particular viewer comment or its opposite was mentioned in only one interview about the artist, it was not tallied. Finally, if the content of a viewer conjecture about an artist was not mentioned directly or indirectly in any interview with study participants who knew the artist, it was listed as 'not mentioned'. This process was checked for accuracy by one of the study's peer debriefers, who selected a case at random, and traced the claims made in the results summary back to the data generated for the study. This admittedly strict strategy for assessing levels of agreement between viewing teachers' statements and interview data were used to ensure the robustness of the study's results.

\section{STUDY RESULTS}

\section{Viewer perceptions of artist age and sex}

Overall, the 13 viewing teachers perceived artist age and sex largely incorrectly in all drawing media. (This may have been due to the fact that all of the children were male and of approximately the same age, while viewing teachers may have assumed that the artists were of both sexes and a range of ages.) As can be seen in Table 1, viewing teachers were able to correctly perceive artist age ( \pm 1 year) from Logo drawings slightly better (50 per cent correctly perceived) than they were able to determine age from graphics-tablet drawings (42 per cent correct) and freehand drawings (38 per cent correct). The differences among media for correct perception of the artist's sex were even smaller: 52 per cent correctly perceived after viewing freehand pictures, 45 per cent for Logo pictures and 37 per cent for graphics tablet pictures. On the average, age was perceived correctly 43 per cent of the time and sex was perceived correctly 45 per cent of the time. Seven teachers assessed age correctly more often than sex, and six teachers assessed sex correctly more often than age.

Viewing teachers displayed a fair amount of individual difference in correct perception of artist age and sex. Percentages of correct age estimation ( \pm 1 year) ranged from 23 to 63 per cent, with an average of 44 per cent. Percentages of correct perception of artist sex ranged from 20 to 63 per cent, with an average of 45 per cent.

There seemed to be no direct relationship between viewing teachers' instructional or computing experience and their abilities to correctly assess artist age and sex. Teacher $\mathrm{N}$ identified the fewest artist ages and genders correctly. Teacher G 
perceived artist age most accurately, and Teacher I identified artist sex correctly most often. Teachers G, I and L had the most years experience combined in all categories: (a) in teaching, (b) using computers, (c) using computers with children, (d) using Logo and (e) using Logo with children. Yet teacher L's accuracy rate was much lower than that of the other two most experienced teachers who viewed the children's artwork. Teacher $\mathrm{N}$, who identified the fewest artist ages and

Table I Numbers of viewing teachers' correct perceptions of artist age and sex, differentiated by media and summed across viewers

\begin{tabular}{llll}
\hline \multirow{2}{*}{$\begin{array}{l}\text { Media } \\
\text { used by } \\
\text { artist }\end{array}$} & \multicolumn{2}{l}{ Artist attribute } & \\
\cline { 2 - 4 } & $\boldsymbol{n}^{\mathbf{a}}$ & Age & Sex \\
\hline $\begin{array}{l}\text { Freehand } \\
\begin{array}{l}\text { Graphics } \\
\text { tablet }\end{array}\end{array}$ & 130 & $50(38 \%)$ & $68(52 \%)$ \\
Logo & 130 & $54(42 \%)$ & $48(37 \%)$ \\
\hline
\end{tabular}

Note: Number of viewing teachers $=13$; teacher $\mathrm{K}$ did not complete response forms.

a Each teacher viewed 10 of each type of picture; therefore, 130 responses each for age and gender were collected. sexes correctly, did not have the least number of combined years of experience in these same areas (see Table 2). Teachers with near-average age perception percentages ( $E$ and $F$ ) and near-average sex perception percentages (teachers A, C, E, $F, G, H$ and $M$ ) had varied amounts of experience in the five areas cited.

\section{Generative viewer perceptions of artists}

A total of 595 viewer-supplied comments were written about the artists of the 30 pictures. Viewers were given virtually unlimited space in which to write their open-ended perceptions. There was little difference in the percentages of openended comments supplied for the works of different individual artists.'Jon Marshall's' work received 8 per cent of viewer comments on the lower end of the continuum, and 'Drew Campbell's' pictures received 13 per cent of the viewers' voluntary comments on the opposite end. Although the numbers of comments supplied for different artists were not that different from each other, percentages of

Table 2 Viewing teachers' professional experience

\begin{tabular}{|c|c|c|c|c|c|c|c|c|c|c|c|c|c|c|}
\hline \multirow[t]{2}{*}{ Years $^{a}$} & \multicolumn{14}{|c|}{ Teacher } \\
\hline & $\mathbf{A}$ & B & C & D & $\mathbf{E}$ & $\mathbf{F}$ & $\mathbf{G}$ & $\mathbf{H}$ & $\mathbf{I}$ & J & $\mathbf{K}$ & $\mathbf{L}$ & M & $\mathbf{N}$ \\
\hline Teaching & 15 & 5 & 6 & 11 & 4 & 5 & 17 & 18 & 27 & 25 & 15 & 32 & 5 & 8 \\
\hline Computers $^{\mathrm{b}}$ & 10 & 4 & 3 & 5 & 3 & 8 & 15 & 8 & 10 & 6 & 10 & 14 & 2 & 5 \\
\hline Children $^{c}$ & 8 & 4 & 2 & 2 & 3 & 4 & 10 & 8 & 10 & 4 & 8 & 9 & 2 & 2 \\
\hline $\operatorname{Logo}^{d}$ & 6 & 1 & 1 & 1 & 3 & 3 & 8 & 5 & 6 & 4 & 4 & 2 & 2 & 1 \\
\hline W/Children ${ }^{e}$ & 4 & 1 & 1 & 1 & 3 & 3 & 8 & 5 & 5 & 2 & 4 & I & 2 & 1 \\
\hline Total ${ }^{f}$ & 43 & 15 & 13 & 20 & 16 & 23 & 58 & 44 & 58 & 41 & 41 & 58 & 12 & 17 \\
\hline
\end{tabular}

${ }^{a}$ Number of years of experience.

bNumber of years using computers.

'Number of years using computers with children.

${ }^{d}$ Number of years using Logo.

eNumber of years using Logo with children.

${ }^{\text {f}}$ This number is provided only for among-teacher comparative purposes. It has no true mathematical value. 
Table 3 Numbers of comments supplied about artists separated by accordance with interview data

\begin{tabular}{|c|c|c|c|c|}
\hline \multirow[t]{2}{*}{ Artist } & \multirow[t]{2}{*}{$n^{\mathbf{a}}$} & \multicolumn{3}{|c|}{ Relationship to interview data } \\
\hline & & Agreement & Disagreement & Not mentioned \\
\hline Drew & 78 & $54(69 \%)$ & $13(17 \%)$ & II (I4\%) \\
\hline Mark & 60 & $43(72 \%)$ & $12(20 \%)$ & $5(8 \%)$ \\
\hline Lance & 59 & $40(68 \%)$ & $12(20 \%)$ & 7 (12\%) \\
\hline Jon & 49 & $31(63 \%)$ & $10(21 \%)$ & $8(16 \%)$ \\
\hline James & 55 & $4 \mathrm{I}(75 \%)$ & $10(18 \%)$ & $4(7 \%)$ \\
\hline Sid & 62 & 47 (76\%) & $10(16 \%)$ & $5(8 \%)$ \\
\hline Bruce & 56 & $33(59 \%)$ & $16(28 \%)$ & 7 (13\%) \\
\hline Rick & 56 & $33(68 \%)$ & $13(23 \%)$ & $5(9 \%)$ \\
\hline Herb & 67 & $46(69 \%)$ & $16(24 \%)$ & $5(7 \%)$ \\
\hline Harvey & 53 & $36(68 \%)$ & $16(30 \%)$ & $\mathrm{I}(2 \%)$ \\
\hline
\end{tabular}

${ }^{a}$ Total numbers of comments offered about each artist.

Table 4 Number of comments supplied by viewers separated by accordance with interview data

\begin{tabular}{lcccc}
\hline \multirow{2}{*}{ Teacher } & $\boldsymbol{n}^{\mathbf{a}}$ & \multicolumn{2}{c}{ Relationship to interview data } \\
\cline { 2 - 4 } & & Agreement & Disagreement & Not mentioned \\
\hline A & 112 & $35(76 \%)$ & $24(21 \%)$ & $3(3 \%)$ \\
B & 25 & $15(60 \%)$ & $6(24 \%)$ & $4(16 \%)$ \\
C & $12(52 \%)$ & $6(26 \%)$ & $5(22 \%)$ \\
D & 23 & $5(71 \%)$ & $2(29 \%)$ & $0(0 \%)$ \\
E & 7 & $7(64 \%)$ & $1(9 \%)$ & $3(27 \%)$ \\
F & 11 & $13(87 \%)$ & $2(13 \%)$ & $0(0 \%)$ \\
G & 15 & $93(75 \%)$ & $22(18 \%)$ & $9(7 \%)$ \\
H & 124 & $62(71 \%)$ & $20(23 \%)$ & $5(6 \%)$ \\
I & 87 & $11(61 \%)$ & $20(30 \%)$ & $6(9 \%)$ \\
J & 67 & $(61 \%)$ & $5(28 \%)$ & $2(11 \%)$ \\
K & 18 & $34(71 \%)$ & $12(25 \%)$ & $2(4 \%)$ \\
L & & $13(59 \%)$ & $0(0 \%)$ & $9(41 \%)$ \\
M & 43 & $13(54 \%)$ & $2(8 \%)$ & $9(38 \%)$ \\
N & 22 & & & \\
\hline
\end{tabular}

${ }^{\mathrm{a} T o t a l}$ numbers of comments offered by each viewing teacher.

viewer-supplied comments that could be substantiated with interview data were quite different for different artists (see Table 3). The range of percentages for comments that agreed with interview data was 50-76 per cent; $16-30$ per cent for comments that disagreed with interview data and 2-16 per cent of the comments that were offered by viewers that did not appear in interview data.

Individual teachers' percentages of interview-substantiated open-ended comments ranged from 52 per cent
(Teacher C) to 87 per cent (Teacher F), as shown in Table 4. These perceptual performance figures were not paralleled by either years of teaching experience or correct perceptions of age and gender. Teacher $\mathrm{E}$ is the only teacher to perceive age, gender and viewer-supplied artist attributes similarly; her scores were close to the group's averages in each instance.

Although there were individual differences among viewing teachers concerning the total number of comments offered in 
response to the artwork, the teachers with the highest percentages of interviewsubstantiated comments were not those who also made the most conjectures.

\section{Perceptions according to drawing media}

Of the 595 total unprompted comments about the artists that were offered by the viewing teachers, 235 (39 per cent) were inspired by viewing freehand drawings, 207 (35 per cent) were offered in response to viewing pictures created with a touchsensitive graphics tablet and 153 (26 per cent) were recorded when looking at pictures created with Logo. Although freehand media seemed to catalyse more unprompted comments than graphicstablet creations, and these pictures, in turn, inspired more viewer comments than Logo pictures, percentages of interviewsubstantiated artist perceptions were roughly equivalent (freehand: 68 per cent; graphics tablet: 70 per cent; Logo: 69 per cent; see Table 5). This is particularly interesting, considering that the viewers commented informally to their instructors that they felt as if they 'knew' the artists better when looking at their freehand drawings.

Overall, 69 per cent of viewers' comments about artists agreed with interview data, 21 per cent disagreed with interview data and 10 per cent were comments that were not mentioned in interviews by any of the three participants giving information about a particular artist. When compared with the percentages for correct perception of artist age (43 per cent) and sex (45 per cent), an interesting difference can be observed. It appears that more individualised (and probably less likely to be guessed at random), intuited information about the artists was verifiable to a greater extent than less individualised artist information (such as age and sex) among the 13 viewing teachers who participated in the study. Again, this may have been due to the homogeneous nature of the artist sample with reference to age and sex. The viewing teachers may have assumed a broader range of participant characteristics than what was used.

This research was a study of individuals; ten individual artists and the perceptions of 13 individual teachers. It explored whether certain aspects of the ten fifthgraders' individualities were communicated to Logo-using teachers through free-form artistic works created in three different media. Although no statistical generalisations can be made from a multicase exploratory study with a small sample such as this one, patterns across participant groups and among individuals can be noted. These should be considered trustworthy for this particular group of study participants because of the methodological rigor demonstrated in data collection and analysis, ${ }^{35}$ as described above.

Table 5 Numbers of verified statements by viewing teachers separated by drawing media

\begin{tabular}{lllll}
\hline $\begin{array}{l}\text { Media used by } \\
\text { artist }\end{array}$ & $\boldsymbol{n}^{\mathbf{a}}$ & \multicolumn{3}{l}{ Relationship to interview data } \\
\cline { 3 - 4 } & & Agreed & Disagreed & Not mentioned \\
\hline Freehand & 235 & $159(68 \%)$ & $47(20 \%)$ & $29(12 \%)$ \\
Graphics tablet & 207 & $145(70 \%)$ & $42(20 \%)$ & $20(10 \%)$ \\
Logo & 153 & $106(69 \%)$ & $39(25 \%)$ & $8(5 \%)$ \\
\hline
\end{tabular}

${ }^{\text {aT } T o t a l ~ n u m b e r s ~ o f ~ s t a t e m e n t s ~ s u p p l i e d ~ b y ~ v i e w e r s ~ f o r ~ a l l ~ p i c t u r e s ~ d r a w n ~ w i t h ~ t h e s e ~ m e d i a . ~}$ 


\section{Results—individual students}

Certainly no teacher or group of teachers in this study described any of the artists with the rich detail revealed by combining the students' self-reports with parental and classroom teacher interview data. Yet, the freehand and computer-facilitated artwork of seven of the ten child informants generated unique viewer comments or patterns of viewer comments (see Figure 1). For example, Drew was described as 'impatient with mistakes' and 'happy and serious'. Mark, it was suspected, 'combines and builds on knowledge', and was described as 'talkative' and 'securityoriented'. Lance's Language Arts proficiency, emphasising fine arts applications, was intuited by several viewing teachers; he was also one of only two children in this group who was described as 'generally a compliant kid'. James had 19 comments made in response to his drawings that mentioned neatness, concern with detail, precision, and related-work-habit

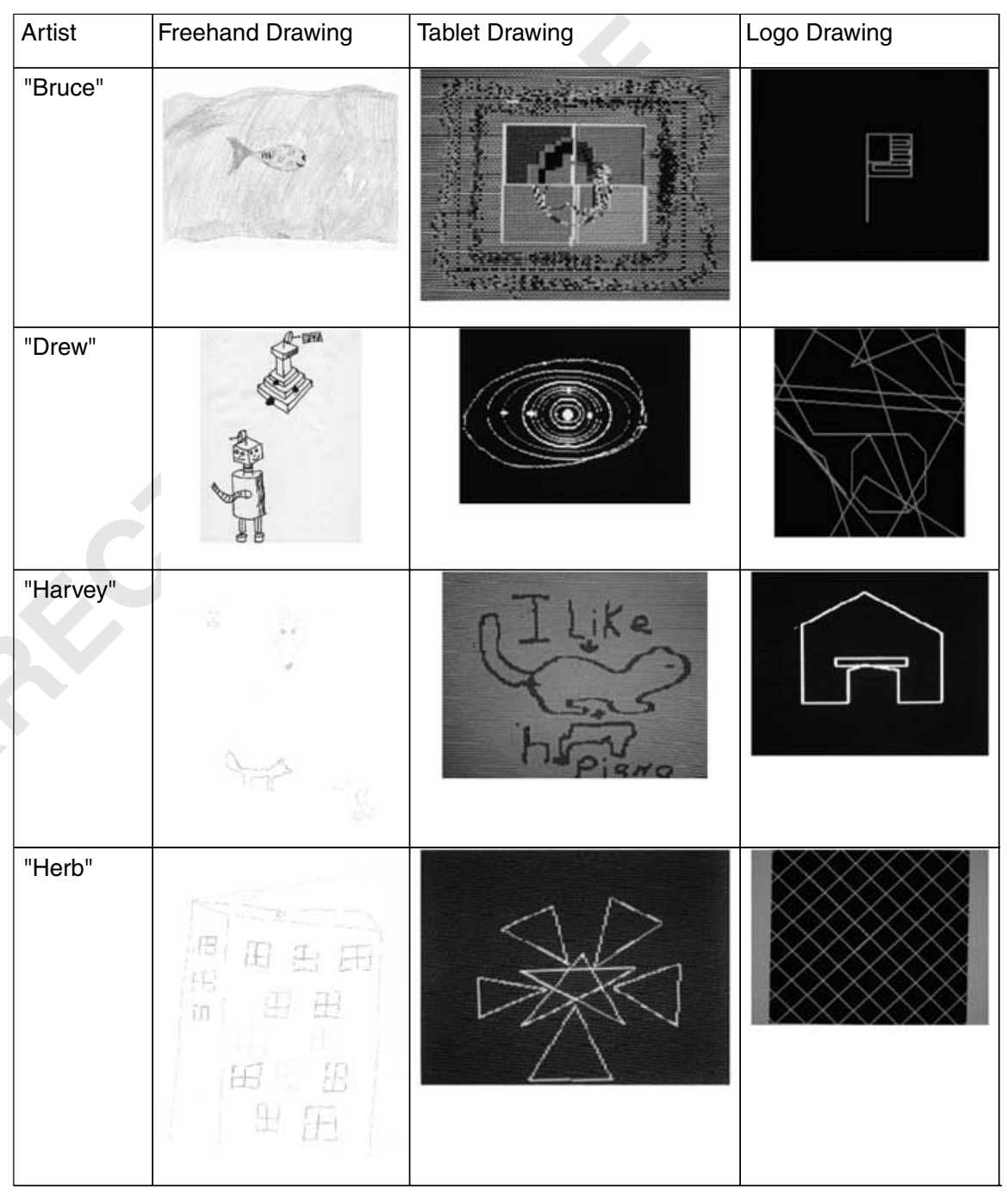

Figure I Sample participant drawings 


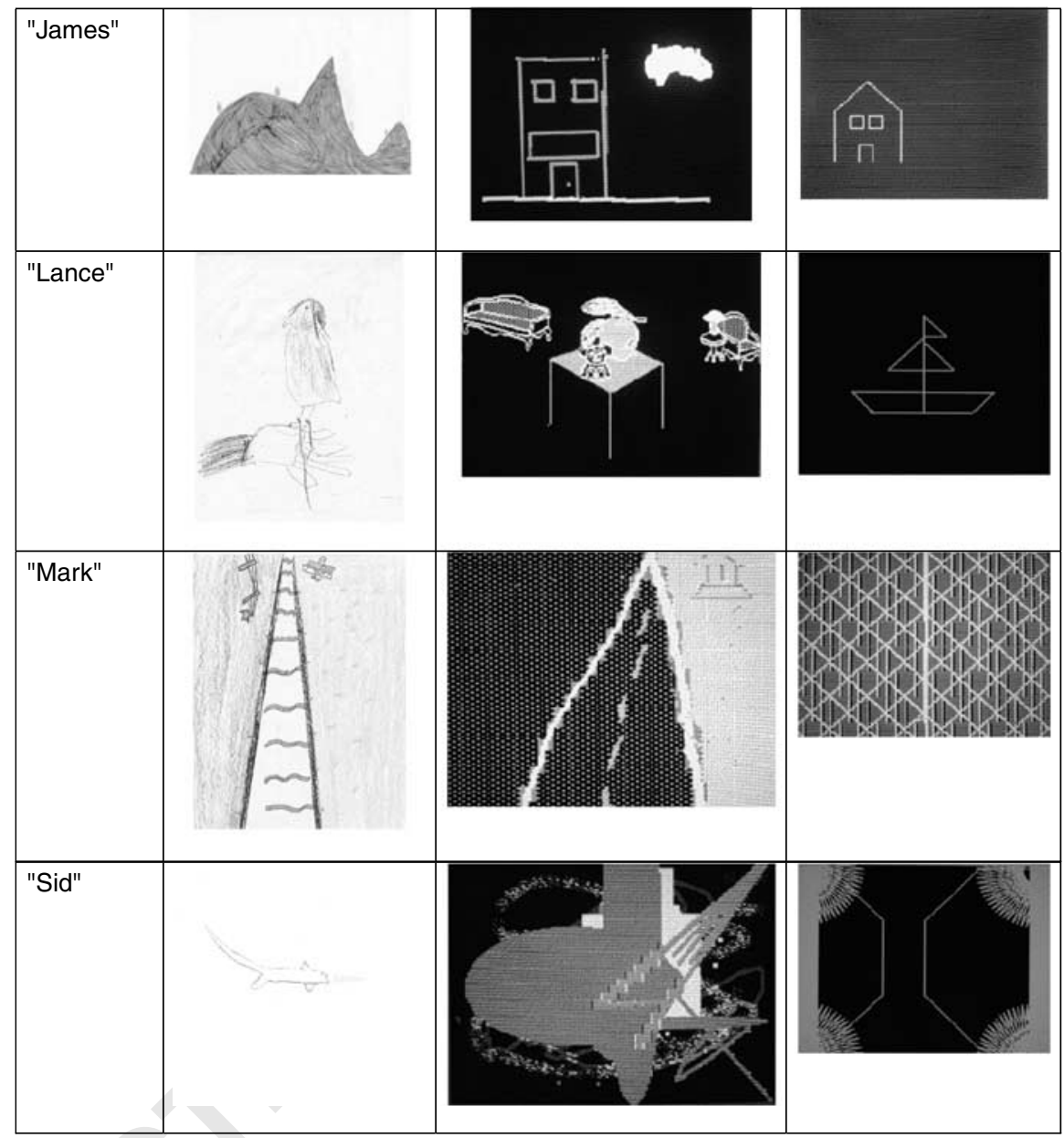

attributes. Sid was collectively portrayed as 'bold', 'adventuresome', 'restless', 'creative' and a 'divergent thinker'. Herb was suspected to have a 'strong personality', and to be a 'quiet', 'intense individual with definite goals'. Harvey's interests in science and animal study were mentioned by several viewers; he was also described as 'impulsive', 'in a hurry' and 'want[ing] to "get it right". These artists' works are displayed in the table below.

Although 'getting it right' was mentioned for several of the child informants during interviews (eg Drew and James), Harvey was the only artist whose artwork communicated attention to appearing 'right'. This paralleled the frequency with which this concern was voiced by his father and teacher.

Although these attributes do not fully portray each individual artist's uniqueness, they are characteristics that begin to differentiate the artists from each other as unique individuals.

More importantly, these distinguishing characteristics were indeed communicated through drawings to viewing teachers who had no other personal information available about the artists, along with other attributes (such as mathematics or science interest) that were more commonly perceived. Also, there were clearly observ- 
able individual differences between children such as Sid and James, who had the highest percentages of interview-substantiated viewer comments, and a child such as Bruce, who had the lowest percentage of such comments. It is apparent that some of the children in this study were more or less 'intuitively readable' through their artwork than others were. It is difficult to suggest why that may be so.

\section{Results across students}

As stated earlier, the teachers in this study were not able, overall, to correctly discern artist age or sex-probably because they were expecting mixed-age and -sex artist characteristics in the range of drawings displayed for their impressions. It should be noted that these results are not characteristic of related research in education and psychology $\left(\mathrm{eg}^{16-18,42,43}\right)$. Generally, artist sex and age are discernible by viewers with a relatively high level of accuracy. The discrepancy revealed in the results of this particular study probably had more to do with the homogeneous nature of the artist sample than the perceptive abilities of the viewing teachers.

It is interesting to note that eight of the ten student artists listed science as one of their preferred subjects in school, and seven of the ten mentioned mathematics as a favourite subject. These preferences were noted by many of the viewing teachers when they were considering pictures that the boys created in all three media. It would seem, therefore, that mathematics or science interest was not intuited primarily as a function of proficient use of a mathematically oriented expressive medium such as Logo.

It is also interesting to note that most viewer comments were made with regard to student work habits, and the least were made concerning students' physical features or capabilities. Any comments that were offered about emotional attributes or interpersonal behaviour patterns were 'positively' stated, or worded as apparent evidence of well-adjusted psychological orientations, even when several of the students had emotional and interpersonal concerns voiced about them by the adults interviewed (eg Harvey, Herb and Lance). This absence is especially interesting when viewed in light of the voluminous psychological literature that primarily addresses the emotional content of children's pictures. It is conceivable either that emotional and physical characteristics were more difficult to discern from these children's drawings than intellectual and work habit attributes, or that the teachers in this study paid closer attention to students' intellectual characteristics and work habits than to other attributes due to the nature of their professional work with children.

\section{DISCUSSION AND REVIEW}

Readers may wonder how probable it is that the patterns documented in this study of children's artwork and teachers' perceptions would also be discernible using adults' graphic designs and consumers' perceptual intuitions. Part of the answer to this question rests with the communicative equivalence of children's and adults' artwork, which has been suggested by the use of both in the psychoassessment literature reviewed earlier (eg Silver, ${ }^{16-18}$ ), with similar results across age groups.

As to the communicative equivalence of design and fine art creations, scholars have linked design aesthetics to artistic production and perception for more than 70 years, beginning with Read's first publication of Art and Industry ${ }^{44}$ in 1934. Read was among the earliest of the 20th century design scholars to discuss the 
aesthetic in the functional directly, saying: 'objects designed primarily for use appeal to the aesthetic sensibility as abstract art;' and the designer as artist, whose 'problem is to adapt the laws of symmetry and proportion to the functional form of the object that is being made' (p. 49). Frascara $^{45}$ summarises this notion by reminding us that graphic design and art have more in common with each other than simply promoting a visual aesthetic. Both design and art affect the behaviour, attitude, and conduct of their respective audiences. Communication is the common denominator-and such semiotic exchange via visual media is clearly worth the attention of brand management researchers and practitioners.

How, then, can we bridge these research results in education with knowledge that may assist scholarship in marketing? This study of the perceived content of children's artwork was, of course, not a study of brand symbols or logos. As such, the results reported here should probably not be used to inform brand management practice directly. Instead, the unexpectedly high percentage (69 per cent) of verifiable unprompted comments made by remotely located viewing teachers about 10 student artists could raise a set of potentially useful questions for future marketing inquiry and practice. Do all graphic creations have similarly communicative aspects with reference to their creators? If not, what causes differences in their communicativeness? Are certain viewers more or less adept at perceiving information about artists through their works, and if so, what gives rise to those differing perceptual abilities? Do the nature or extent of the works' communicative qualities differ with respect to particular artist attributes? Can the content of this symbolic communication be consciously enhanced? Can such semiotic information about works' creators be intentionally shaped, masked or changed? The answers to questions such as these could direct productive, and eventually helpful, brand management research.

The results of this study do recommend several directions in which brand development scholarship could be developed and brand management practiced. Classroom teachers are not trained directly to identify students' personality traits from their artwork. This fact, considered together with psychological research that demonstrated the equivalence of trained and untrained judges' assessments of Human Figure Drawings mentioned earlier, ${ }^{24,25}$ suggests that if 69 per cent of teachers' statements about the artists' attributes in this study were correct, then it's possible - if not probable-that consumers have similar unconscious, intuitively perceptive abilities. If teachers are not trained to assess children's traits from viewing their artistic creations, but they can do so with a comparatively high level of accuracy, then their abilities may have been developed by repeated exposure to children and their works.

The number of logos and other advertising-related images that the average consumer sees every day is probably increasing over time with rapid advances in multimedia tools' affordances and communication bandwidth available. If perceptiveness about artist attributes is primarily a function of exposure to images, then the average consumer may have perception similarly accurate to the teachers in this study. One way to interpret Moss and colleagues ${ }^{10-13}$ repeated results showing preferences for products created by designers of the same sex as viewers would be to support this notion of consumers' general perceptive ability when viewing artistic works, since these study participants were not teachers.

Yet preferring works created by designers of the same sex as viewers-as 
participants in Moss and colleagues' multiple studies did-is not the same as intuiting and stating accurately a range of information about artists after viewing their creations, as the teachers in the present study did. It is probable that participating teachers were able to do this based upon previous professional experience working closely with children at different developmental levels, observing their behaviour and products while doing so. Whether consumers can be similarly perceptive and expressive about brand designers' personal attributes remains to be seen. Even if they cannot, however, the strong 'like for like' preferences that Moss surfaced, working singly or in conjunction with Colman on the one hand, and Gunn on the other, suggest that similarly matched consumer preferences may well exist for schematic attributes beyond sex, such as age, ethnicity or educational level; or situational attributes, such as mood, as Aaker's ${ }^{7}$ explorations of the 'malleable self' demonstrate.

This suggests one of at least two possible courses of action for brand development scholarship and practice. Marketing researchers could learn either how to consciously imbue media creations with attributes or messages that mirror schematic and/or situational consumer attributes; or consciously seek out brand developers with attributes and/or sensibilities similar to those of the brand's target audiences, assuming that the designers will unconsciously incorporate personal attributes and aesthetics into their works. Until these mirroring phenomena are better understood, it would be wise to encourage the expression of multiple cultures, genders, ages and personal orientations in brand designs, and the employment of brand designers whose personal attributes, aesthetics and experiences match target consumer audiences as closely as possible.
Such action could not only better serve specific brand marketing objectives; it could also serve the field in a larger sense, opening brand development work to the ever-growing diversity of our nations' professional populations. In following these suggestions, brand development professionals would be making and acting upon the kinds of discoveries that Szent-Gyorgyi ${ }^{1}$ identified long ago, and with which this paper began: those that result from seeing what everyone else sees, but thinking differently.

\section{References}

(1) Who Named It? [database on the Internet]. Oslo: Whonamedit.com (Norway); n.d.-[cited 2006 Jun 17]. Albert Szent-Györgyi von Nagyrapolt; [about 1 p.]. Available from:. http://www. whonamedit.com/doctor.cfm/1542.html Files last updated 2001.

(2) Carini, P. F. (1979) 'The Art of Seeing and the Visibility of the Person', North Dakota Study Group on Evaluation, Grand Forks (ND).

(3) Crozier, W. R. and Greenhalgh, P. (1992) 'The empathy principle: Towards a model for the psychology of art', Journal for the Theory of Social Behaviour, Vol. 22, No. 1, pp. 63-79.

(4) Aaker, D. A. (1991) 'Managing Brand Equity: Capitalizing on the Value of Brand Name', Free Press, New York.

(5) Aaker, J. L. (1997) 'Dimensions of brand personality', Journal Marketing Research, Vol. 34, pp. 347-356.

(6) Karande, K., Zinkhan, G. M. and Lum, A. B. (1997) 'Brand personality and self concept: A replication and extension', American Marketing Association Educators' Proceedings, pp. 165-171.

(7) Aaker, J. L. (1999) 'The malleable self: The role of self-expression in persuasion', Journal of Marketing Research, Vol. 36, pp. 45-57.

(8) Batra, R., Lehmann, D. L. and Singh, D. (1993) 'The brand personality component of brand goodwill: Some antecedents and consequences', in Aaker D. A. and Biel A. (eds) Brand Equity and Advertising', Lawrence Erlbaum, Hillsdale, NJ, pp. 83-96.

(9) Buchanan, R. (1995) 'Rhetoric, humanism, and design', in Buchanan R. and Margolin V. (eds) Discovering Design-Explorations in Design Studies', University of Chicago Press, Chicago, IL, pp. 23-66.

(10) Moss, G. (1995) 'Differences in the design aesthetic of men and women: Implications for product branding', Journal of Brand Management, Vol. 3, No. 3, pp. 51-61. 
(11) Moss, G.A. (1999) 'Gender and consumer behaviour: Further explorations', Journal of Brand Management, Vol. 7, No. 2, pp. 88-100.

(12) Moss, G. A. and Colman, A. (2001) 'Choices and preferences: Experiments on gender differences', Journal of Brand Management, Vol. 9, No. 2, pp. 89-98.

(13) Moss, G. A. and Gunn, R. W., Websites and services branding: implications of universities' websites for internal and external communication. Cambridge (UK): 4th International Critical Management Studies Conference; 2005; http:// www.mngt.waikato.ac.nz/ejrot/cmsconference/2005/proceedings/virtualitychallenge/ proceedings_virtualitychallenge.asp.

(14) Rogoff, I. (1998) 'Studying visual culture', in Mirzoeff N. (ed.) The Visual Culture Reader', Routledge, New York, NY, pp. 3-26.

(15) Fischman, G. E. (2001) 'Reflections about images, visual culture, and educational research', $E d$ Researcher, Vol. 30, No. 8, pp. 28-33.

(16) Silver, R. A. (1987) 'Sex differences in the emotional content of drawings', Art Therapy, Vol. 4, No. 2, pp. 67-77.

(17) Silver, R. A. (1992) 'Gender differences in drawings: A study of self-images, autonomous subjects, and relationships', Art Therapy, Vol. 9, No. 2, pp. 85-92.

(18) Silver, R. A. (1993) 'Age and gender differences expressed through drawings: A study of attitudes toward self and others', Art Therapy, Vol. 10, No. 3, pp. 159-168.

(19) Klepsch, M. and Logie, L. (1982) 'Children Draw and Tell: An Introduction to the Projective Uses of Children's Human Figure Drawings', Brunner/ Mazel, New York.

(20) Goodenough, F. (1926) 'Measurement of Intelligence by Drawings', Harcourt, Brace \& World, Chicago.

(21) Harris, D. B. (1963) 'Children's Drawings as Measures of Intellectual Maturity', Harcourt, Brace and World, New York.

(22) Harris, D. B. and Roberts, J., (Department of Health, Education, and Welfare, Washington, DC). Intellectual maturity of children: demographic and sociometric factors. 1972; Report No. 116, Vital and Health Statistics Series 11.

(23) Milne, L. C., Greenway, P. and Best, F. (2005) 'Children's behaviour and their graphic representation of parents and self', Arts in Psychotherapy, Vol. 32, No. 2, pp. 107-119.

(24) LaVoy, S. K., Pedersen, W. C., Reitz, J. M., Brauch, A. A., Luxenberg, T. M. and Nofsinger, C. C. (2001) 'Children's drawings: A cross-cultural analysis from Japan and the United States', School Psychology International, Vol. 22, No. 1, pp. 53-63.

(25) Thomas, G.V. and Jolley, R. P. (1998) 'Drawing conclusions: A re-examination of empirical and conceptual bases for psychological evaluation of children from their drawings', British Journal of Clinical Psychology, Vol. 37, No. 2, pp. 127-139.

(26) Lilienfeld, S. O., Wood, J. M. and Garb, H. N. (2000) 'The scientific status of projective techniques', Psychology Science in the Public Interest, Vol. 1, No. 2, pp. 27-66.

(27) Swensen, C. (1968) 'Empirical evaluations of Human Figure Drawings: 1957-1966', Psychology Bulletin, Vol. 70, pp. 20-44.

(28) Hiler, E. and Nesvig, D. (1965) 'An evaluation of criteria used by clinicians to infer pathology from figure drawings', Journal of Consulting Psychology, Vol. 29, pp. 520-529.

(29) Noddings, N. and Shore, P. J. (1984) 'Awakening the Inner Eye: Intuition in Education', Teachers College Press, New York.

(30) Harris, J. B. (1990) 'The Scope and Interjudge Agreement of Information Communicated Through Children's Computer-Facilitated and Freehand Drawings [Dissertation]', University of Virginia, Charlottesville (VA).

(31) Yin, R. K. (2002) 'Case Study Research: Design and Methods', 3rd edn, Sage Publications, Newbury Park, CA.

(32) Stake, R. E. (1995) 'The Art of Case Study Research', Sage Publications, Thousand Oaks, CA.

(33) Miles, M. B. and Huberman, A. M. (1994) 'Qualitative Data Analysis: An Expanded Sourcebook', Sage Publications, Thousand Oaks, CA.

(34) Patton, M. Q. (2002) 'Qualitative Research \& Evaluation Methods', 3rd edn, Sage Publications, Thousand Oaks, CA.

(35) Strauss, A. and Corbin, J. (1998) 'Basics of Qualitative Research: Techniques and Procedures for Developing Grounded Theory', 2nd edn, Sage Publications, Thousand Oaks, CA.

(36) Lincoln, Y. S. and Guba, E. G. (1985) 'Naturalistic Inquiry', Sage Publications, Newbury Park, CA.

(37) Touch Window [Computer Peripheral]. (1985) Touch Screens, Inc., Lilburn, GA.

(38) Animation Station [Software]. (1984) SunCom, Wheeling, IL.

(39) Logo Computer Systems, Inc. (1983) 'IBM Logo [Software]', LCSI, New York.

(40) Logo Computer Systems, Inc. (1984) 'Apple Logo II [Software]', LCSI, New York.

(41) Logo Computer Systems, Inc.. (1986) 'LogoWriter for the Apple II [Software]', LCSI, New York.

(42) Chen, W. J. and Kanter, L. A. (1996) 'Gender differentiation and young children's drawings', Vis Arts Res, Vol. 22, No. 1, pp. 44-51.

(43) McNiff, K. (1982) 'Sex differences in children's art', Journal of Education, Vol. 164, No. 3, pp. 271-289.

(44) Read, H. (1934) 'Art and Industry', Sage Faber and Faber, London, UK.

(45) Frascara, J. (1988) 'Graphic design: Fine art or social science?', Design Issues, Vol. 5, No. 1, pp. $18-29$. 